\title{
Exploring Implications of Categories: Categorical Stereotypes in Organizational Research
}

\author{
Abiodun (Abi) Ige \\ University of Detroit Mercy
}

The paper introduces categorical stereotypes to the literature on organizations categories. Stereotypes are information that can be transferred from group level to individual members of the group; to understand how firms respond to been categorized, scholars must account for the stereotypes associated with the categories. Stereotypes also influence audiences' actions towards categorized firms; audiences go beyond judging organizations based on their categorical purity and consider information signals coming from stereotypes on the underlying categories. We explore the implications of categorical stereotypes on ongoing discourse on firm categories and on managerial actions.

Keywords: categories, markets, stereotypes, SCM, BIAS map

\section{INTRODUCTION}

Over the last two decades, organizational and strategic management scholars have increasingly focused on categorization processes as fundamental to understanding firm behaviors (Delmestri \& Greenwood, 2016; Durand \& Paolella, 2013; Glynn \& Navis, 2013; Vergne, 2012; Vergne \& Wry, 2014; Wry, Lounsbury, \& Jennings, 2014). The central thrust of this literature is how categories shape perceptions and actions of organizations and their audiences. Categories are socio-cognitive constructs; scholars argue that categories, by shaping cognitions, influence the actions of firms and their audiences. However, the links between categorical cognitions and category-based actions are underspecified. In this paper, we seek to broaden the scope of categorization research by introducing stereotypes (and their consequences) as important links between categorical-based perceptions and actions of audiences and reactions of categorized firms. By doing so, we raise important issues for future research, including a focus on the sources and consequences of inequality and status in and across categories.

Categories are groupings of entities with some similarities. In organization studies, categories refer to groups of similar firms. However, management scholars do not theorize what it means to be members of categories. In other academic fields, scholars pay as much attention to the contents of categories as they do to the groups. The contents of a category say a lot about the category's members. Some scholars frame the contents of categories as stereotypes. Stereotypes are forms of information audiences hold about social groups; stereotypes are also the social meaning of categories (Brubaker, Loveman, \& Stamatov, 2004). Pragmatically, when audiences think about categories, they also think about the stereotypes attached to those categories. Stereotyped labels can be used as a social resource, but they also come with a social cost. These resources or costs can make actors desire to be members of some social groups instead of others. This is because stereotypes can enable members of categories gain support and legitimacy for their actions. 
For example, firms labelled as environmentally friendly may easily get approvals for projects with uncertain environmental outcomes. Conversely, local firms that deviate from the expectations of care for local people and resources may suffer more severe blowback than non-local firms in similar situations.

A firm's actions can reinforce, reshape, and/or dispel the labels of its categories (Delmestri \& Greenwood, 2016). Similarly, stereotypes often lead to status ordering of categories; that is, audiences prefer some categories to others because of the attached stereotypes. These preferences can lead to status ordering of categories (Sharkey, 2014). That firms prefer to belong to one group over others can inform ongoing debates in organization studies; in addition, these preference can also contribute to our understanding of how firm stereotypes change (Delmestri \& Greenwood, 2016; Sharkey, 2014).

Understanding stereotypes can contribute to studies of firms' categories. Positive stereotypes about being sustainable might mean firms might suffer smaller blowback for environmental infractions. Sharkey (2014) argued that high-status category firms that restated their financial earnings suffered lower abnormal returns. Firms are more likely to cross multiple group boundaries if they are members of groups that have been stereotyped negatively. When firms act to reshape bad group labels, they might end up creating new firm groups. The ridesharing industry is a prime example. Uber, Lyft, and other pioneers in the ridesharing/hailing group might not have wanted to be classified as cab companies; this is partly because of the negative stereotypes/low status associated with the cab category (Anderson, 2014; Wallsten, 2015). Therefore, these firms aligned with the technology group: a category with higher status than the cab group. Labels of groups impact members of social groups; the impacts should be part of what management scholars consider when they discuss firms' social groups. Examining stereotypes might help close the gap between theoretical recommendations and practices. In addition, this approach can open new paths for research on firm grouping.

Previous studies on firm categories suggest firms should reduce the number of market categories in which they operate. These conclusions did not consider the contents of the categories such as stereotypes. Since audiences prefer some stereotypes to others, some firms might want to associate with a preferred organizational group; this often leads firms to membership in multiple firm and/or product groups (Vergne, 2012). That is, there is conflict between what theories on firm categories suggest and what some firms do. Theories advocate for fewer categories, but practices dictate more categories for some firms. We hope to address this conflict in this paper by introducing the concept of categorical stereotypes. We argue that if scholars incorporate the concept of stereotypes into the organizational study of categories, they might understand why some firms span multiple categories.

While we do not go so far as to claim that stereotypes are the only link between category-based cognition and categorical actions, we do believe that attention to stereotypes can greatly enhance our understanding of organizations and their relationship to categorization. Similarly, stereotypes also have other implications for firm categories. Stereotypes often result in different levels of desirability of social categories; that is, these labels can lead to preferential ordering of categories based on audiences' evaluations. These stereotype-based orderings of firm categories can also have important implications for firm strategies.

The remaining part of the paper is arranged in the following sequence. In the next section, we review relevant literature to set the stage for our arguments. We briefly discuss key themes in the organization literature on categorization including the categorical imperative, category emergence, and categorical stigma. After this, we pivot to the social psychology literature on stereotypes and their affective and behavioral outcomes. We connect this social psychology discourse to organization literature on firm categories to make our main arguments about the impact of stereotypes on category-based actions. We conclude the paper with discussions about the consequences that our arguments will have on managerial practice and scholarly research.

\section{EXISTING LITERATURE ON ORGANIZATIONS' CATEGORIES}

Multiple literatures underline our arguments linking stereotypes to category-based actions in organization literature. In the following sections, we examine key insights in these literatures and how they 
relate to the arguments we put forward in this paper. The literature on categorical imperatives introduced category-based arguments to most branches of organization theory. Categorical imperative research suggests that audiences punish actors that cross categorical boundaries. Research on category emergence focuses on organizations' actions leading to the creation and/or emergence of new firm or product categories. In addition to reviewing categorical imperative and category emergence studies, we examined the discourse on how category memberships impact organizations' actions. While some scholars argue that category membership constrains an organization's actions, others suggest that categories enable actions. Recently, scholars examined stigmatized firm groups and how group members address the stigmas attached to their groups.

\section{Categorical Imperative and Category Emergence}

Studies on categorical imperatives suggest that audiences penalize actors that cross group boundaries. Scholars refer to crossing categorical boundaries as category spanning or straddling. Zuckerman (1999, 2000) laid the foundations of categorical imperative arguments in organization studies by pointing out that firms that spanned multiple industry boundaries received less attention from stock analysts, which leads to lower valuation and higher volatility. Zhao et al. (2013) observed similar relationships in feature films spanning multiple genre categories; in addition to the illegitimacy discounts these genre-spanning films suffered, the authors observed that invoking familiar film names was not potent enough to nullify the penalties of straddling (Zhao, Ishihara, \& Lounsbury, 2013). Similarly, Roberts et al. (2010) found that Israeli wine producers crossing the kosher-wine product boundary, i.e., kosher wines versus non-kosher wines, were penalized by audiences who gave the producers lower quality scores compared to winemakers that did not cross the boundary. Other studies qualified the conditions under which spanning led to penalties from audiences. Pontikes (2012) argued that types of audiences determined whether category spanning would lead to penalties. The author suggested that market-takers, such as consumers, relish clear categorical boundaries and therefore punish actors straddling them. Conversely, market-makers, such as venture capitals, are more comfortable with straddling and might even reward categorical spanning (see also Wry et al., 2014). Vergne (2012) argued that straddling can be beneficial for actors that are members of stigmatized firm groups; the author suggested that straddling may divert an audience's attention away from the stigma associated with the base category. Significant scholarly efforts have been expended on understanding categorical imperative and the punishing consequences of spanning multiple industry and product groups. These studies suggest that audiences' actions are directly linked to group membership. However, we argue that the links between categorical cognition and audiences' actions are underspecified.

How new categories emerge also piqued scholarly interest. Given that categories often shape audiences' perceptions and that non-grouped entities tend to be overlooked, scholars have wondered how new categories gain currency (Kennedy 2008). Jones et al. (2012) showed how architects holding different institutional logics negotiated the creation of a new category: modern architecture. The architects creatively enacted flexible artifact codes by mixing old and new materials in modern buildings (Jones, Maoret, Massa, \& Svejenova, 2012). Schultz et al. (2014) argued that media coverage of new market activities plays a pivotal role in legitimizing new market categories (see also Kennedy, 2008). Going beyond product- and producer-based categories, Diestre and Rajagopolan (2014) made a case for the emergence of input-based firm groups. The authors argued that highly publicized accidents about a particular input created negative spillovers for firms using the input, i.e., a form of ad-hoc category advocated by Durand and Paolella (Diestre \& Rajagopalan, 2014; Durand \& Paolella, 2013). Khaire (2014) went beyond the emergence of new categories to determinants of status of new categories; the author argued that framing by early participants in the new category (high-end fashion industry in India) contributed significantly to the high status of the firm group (Khaire, 2014). Ozcan and Santos (2015) examined factors that contributed to the non-emergence of a potentially promising product category: mobile payment. The authors argued that structural positions of the potential new category's promoters made compromises difficult and resulted in the failure of initial cooperative actions geared towards the creation of the product (Ozcan \& Santos, 2015).

While categorical imperative focuses on audiences' actions, categorical emergence focuses on actions of group members. Similarly, the bases of actions are underspecified. Contrastingly, the types of action that 
lead to category emergence are usually active actions (rather than passive actions). Stereotypes can shed light on the antecedence of active actions and inform the drive towards category emergence.

\section{Constraining Effect of Categories on Organization Actions}

Categorical imperative arguments suggest that categories constraint actions of group members and their audiences. That is, because audiences punish atypical members, grouped firms tend to conform. In addition, audiences are construed as preferring clearly defined boundaries; therefore, they favor actors that easily fit within the boundaries of their groups. Some scholars challenged these constraining effects of firm categrories (Durand \& Paolella, 2013; Glynn \& Navis, 2013). They argued that because organization studies of categories are rooted in the prototypical views, scholars thought that the more similar firms are to the group prototype, the better. Durand and Paolella (2013) proposed cause-and-effect-based groupings and goal-based groupings as alternatives to this dominant prototypical view. They said these alternatives are essential to understanding the enabling effects of categories. They further argued that cause-and-effect reasoning can make audiences cobble together groups based on what they know to cause the desired effects. In this case, having the cause automatically put an entity in the ad-hoc group of entities that can create the desired effect; for instance, Diestre and Rajagopolan (2014) found that accidents involving a chemical created an ad-hoc category of firms whose inputs included the focal chemical. Goal-oriented groupings allow audiences and group members to form ad-hoc categories to pursue specific goals. The goal of hosting a major sporting event might create an ad-hoc group of local firms whose patronages and visibilities might be enhanced by the sporting event. Glynn and Navis (2013) argued that the constraining view of categories are products of overly focus on the cognitive ramifications of categories. According to these authors, firm groups are embedded in wider systems of social meanings; conditions in these social contexts can impact the constraints imposed on social groups. Most attempts to link categories to actions, in literature, are rooted in cognition; however, affects are better predictors of action than cognition (Cuddy, Fiske, \& Glick, 2007). Stereotypes link categorical cognitions with different affective dispositions which in turn might better predict actions of audiences and reactions of category members.

\section{Category Stigma}

Several recent studies of organizational categories highlighted the social contents of firm categories (Delmestri \& Greenwood, 2016; Piazza \& Perretti, 2015; Vergne, 2012). These studies showcased audiences' interpretations of category membership. While not using the term stereotype, the studies alluded to categorical stereotypes by drawing attention to social evaluations of group membership rather the purity or lack thereof of group membership. Vergne (2012) focused on stigmatized firm groups and how stigmas lead to social disapproval. The study examined the global armaments industry as a stigmatized product category; some members in the industry were further stigmatized by their countries of origin. The author explained that industry members branched into different product lines to mask the impacts of the stigma associated with their primary industry. The author theorized and showed how category spanning can shield members of stigmatized categories from disapproval. Piazza and Perretti (2015) built on the notion of categorical stigma to show when actors are likely to exit stigmatized product lines. In their study of nuclear reactor units in the United States, the authors argued that a firm's decision to quit stigmatized product lines depends on the intensity of the stigma, media focus on the industry, and the centrality of the stigmatized product to organization's identity. They posited that the only way to escape some stigmas is to break with the associated groups. Taking a different tack, Delmestri and Greenwood (2016) examined how an organization destigmatized its category and reaped the benefits of a high status firm group. Grappa, an Italian alcoholic beverage, was a highly stigmatized product whose reclassification faced stiffed resistance from different audiences; Delmestri and Greenwood (2016) chronicled the different strategic and culturally constrained actions that led to the stigma being removed from the product. Taken together, these studies highlight the importance of categorical contents in motivating organizational actions. However, existing studies focus only on members of stigmatized firm groups and how they work to mask and/or remove their group stigma (Delmestri \& Greenwood, 2016; Piazza \& Perretti, 2015; Vergne, 2012). There are other category contents that are not stigmas. Some firm groups are admired (e.g., information technology firms) 
while others are envied (e.g., investment banks); these emotions directed towards group members can also influence audiences' actions toward group members and reactions of categorized firms (Sharkey, 2014).

\section{CATEGORICAL STEREOTYPES}

By most historical accounts, Lippman (1922) coined the term stereotype as the typical picture that comes to mind when thinking about a particular social group (Dovidio, Hewstone, Glick, \& Esses, 2010). That is, stereotypes are cultural and cognitive representations of social categories. Usually, when audiences perceive social categories, they do not just visualize the prototypical member, they also picture the characteristics that set the group apart from other groups; these characteristics are the categorical stereotypes. Stereotypes are cognitive schema used by audiences to process information about social groups (Dovidio et al., 2010). Stereotypes go beyond the beliefs about members of social groups to include information about groups and can influence emotions directed towards the members (Dovidio et al., 2010). To the best of our knowledge, the literature on categories in organization studies has paid no attention to stereotypes; however, stereotypes are important components of organizational categories. Insomuch as scholars care about audiences' perceptions of firm groups, the tools audiences use to arrange their perceptions must be important to scholars; these tools are stereotypes. Part of the reason that firms respond differently to being categorized is the stereotypes attached to the categories. Table 1 shows the differences between the prototype-based categorization prevalent in organizational studies and the stereotype-based categorization we are proposing.

\section{TABLE 1}

DIFFERENCES BETWEEN PROTOTYPES-BASED CATEGORIZATION AND STEREOTYPEBASED CATEGORIZATION

\begin{tabular}{|l|l|l|}
\hline S/No & Prototypes & Stereotypes \\
\hline $\mathbf{1}$ & $\begin{array}{l}\text { Prototypes facilitate comparisons within } \\
\text { single category. Members are judged by } \\
\text { how similar they are to the prototypical } \\
\text { member. }\end{array}$ & $\begin{array}{l}\text { Stereotypes mainly facilitate comparisons across } \\
\text { multiple categories. Audiences hold stereotypes about } \\
\text { different categories; these stereotypes are often used } \\
\text { to compare the different categories }\end{array}$ \\
\hline $\mathbf{2}$ & $\begin{array}{l}\text { Prototypes are relatively stable across social } \\
\text { contexts, e.g., the prototypical bird in } \\
\text { Europe is like the prototypical bird in the } \\
\text { Americas. }\end{array}$ & $\begin{array}{l}\text { Stereotypes are often products of social contexts and } \\
\text { they varied across context both in time and space. } \\
\text { Social contexts cue stereotyping; that is, some } \\
\text { contexts make stereotypical thinking and behavior } \\
\text { more salient than other contexts. }\end{array}$ \\
\hline $\mathbf{3}$ & $\begin{array}{l}\text { Once established, prototypes are less } \\
\text { sensitive to types of audiences, e.g., } \\
\text { different audiences can similarly identify } \\
\text { organizations as banks, universities, or } \\
\text { hotels }\end{array}$ & $\begin{array}{l}\text { Types of audiences influences group stereotypes, i.e., } \\
\text { different audiences can hold different stereotypes } \\
\text { about same group. For instance, different audiences } \\
\text { have different stereotypes about banks, universities, } \\
\text { or hotels }\end{array}$ \\
\hline $\mathbf{4}$ & $\begin{array}{l}\text { Prototypes are cognitive structures with } \\
\text { minimal affective consequences; that is, } \\
\text { audiences use prototypes to arrange and } \\
\text { understand their world not feel it. }\end{array}$ & $\begin{array}{l}\text { Stereotypes are cognitive structures that can provokes } \\
\text { wide range of emotions towards group members. } \\
\text { Emotions based on stereotypes are often the bases of } \\
\text { ingroup coherence and favoritism as well as outgroup } \\
\text { discriminations. }\end{array}$ \\
\hline $\mathbf{5}$ & $\begin{array}{l}\text { Prototypes, in and of themselves, are value } \\
\text { neutral }\end{array}$ & $\begin{array}{l}\text { Stereotypes are value-laden; that is based on } \\
\text { stereotypes, audiences show preferences for some } \\
\text { categories over others }\end{array}$ \\
\hline $\mathbf{6}$ & $\begin{array}{l}\text { Subcategories in prototype-based categories } \\
\text { usually have features of the main categories }\end{array}$ & $\begin{array}{l}\text { Stereotypes associated with subcategories might be } \\
\text { different from the stereotypes of the main category }\end{array}$ \\
\hline
\end{tabular}


While there have been several attempts to conceptualize the contents of stereotypes, the Stereotype Content Model (SCM) proposed by Susan Fiske and her co-authors is about the most widely used and recognized as capturing categorical stereotypes (Aaker, Vohs, \& Mogilner, 2010; Cuddy, Fiske, \& Glick, 2008; Fiske, Cuddy, Glick, \& Xu, 2002; Halkias, Davvetas, \& Diamantopoulos, 2016). Beyond conceptualizing stereotypes in terms of warmth and competence, the Behavior from Intergroup Affects and Stereotypes (BIAS) map, based on the SCM, also proposes affective and behavioral consequences of stereotypes (Cuddy et al., 2008, 2007). The challenges of linking cognition to behaviors are well documented in psychology literature. Emotions are better predictors of social behavior than cognition. Stereotypes are strong antecedents of emotions directed toward category members. For instance, most audiences stereotype homeless people as generally irresponsible and partly to blame for been homeless. These stereotypes make people hostile to the homeless and less likely to help them. The category homeless, without the associated stereotypes, will be missing vital information that could be a precursor to actions; the same argument applies to firm and product categories. The SCM and the BIAS map theorize the links between categories and actions via stereotypes (Cuddy et al., 2007; Fiske et al., 2002).

\section{SCM and BIAS Map}

While there are many ways to analyze the contents of stereotypes, there seems to be a near consensus among researchers in social and cognitive psychology that the SCM aptly captures how audiences stereotype members of different social groups. The SCM suggests that stereotypes vary along two dimensions: warmth and competence. Using these dimensions, audiences view members of social groups in different ways. Variations along these two components create a conceptual two-by-two partitioning, in which social groups can be stereotyped as either high or low on warmth and competence. Categorical stereotypes can be high warmth, high competence; high warmth, low competence; low warmth, high competence; and low warmth, low competence. Researchers in many fields confirmed the robustness of the SCM and its application to different types of social groups (Aaker et al., 2010; Barbarossa, De Pelsmacker, Moons, \& Marcati, 2016; Halkias et al., 2016; Villano, Fontanella, Fontanella, \& Donato, 2017).

Warmth and competence are two dimensions of stereotypes. Warmth captures the intentions of members of social groups; competence captures their ability to carry out the intentions (Cuddy et al., 2008). Members of a social category are stereotyped as warm if they are perceived to have benevolent intentions towards other categories. Warmth stereotypes are characterized by adjectives such as good-natured, trustworthy, fair, friendly, and tolerant. Members of social groups are considered competent if they are perceived as having a greater capacity to carry out their intentions. Competence stereotypes are associated with words such as efficacy, confidence, intelligence, and skilled. Competition is the primary antecedent of warmth; audiences considered non-competitive others as warm. Perceived status is the primary antecedent of competence; that is, groups considered high status are stereotyped as competent.

\section{Affective and Behavioral Consequences of Stereotypes}

Building on the SCM, Cuddy et al. (2007) introduced the BIAS map; the framework maps different combinations of stereotype contents to emotional and behavioral predilections. Stereotypes not only prompt emotions, but also lead to discriminating actions. Cuddy et al. (2007) argued that different combinations of warmth and competence can provoke emotions that lead to different types of actions. They classify actions resulting from emotions emanating from categorical stereotypes as active or passive in terms of intensity, and facilitation or harm in terms of valence. Ayduk et al. (2003) differentiate active behavior from passive behavior by arguing that active behaviors are direct, overt, intense, explicit, and high risk, while passive behaviors are less intense, indirect, avoidant, and covert (see also Cuddy et al. 2007). In terms of facilitation and harm, Cuddy et al. (2007) differentiate these types of actions as follows: "facilitation leads to ostensibly favorable outcomes or gains for groups; harm leads to detrimental outcomes or losses for groups" (pg. 633). The authors argued that while warmth stereotypes lead to active actions, competence stereotypes lead to passive actions (see Cuddy et al. 2007 for details). Admired categories (i.e., high warmth and high competence) elicit active and passive facilitation; audiences want to help members of these categories (active facilitation) and associate with them (passive facilitation). The despised categories (i.e., low warmth 
and low competence) elicit active and passive harm; audiences do not want to help them (active harm) and do not want to associate with them (passive harm). While the pitied categories (high warmth and low competence) elicit active facilitation (i.e., audiences want to help them) and passive harm (i.e., audiences do not want to associate with them), the envied categories (low warmth and high competence) elicit active harm (i.e., audiences do not want to help them) and passive facilitation (audiences want to associate with them). Categorical stereotypes can lead to emotions that orient audiences' actions towards members of the underlying categories. Figure 1 shows the configuration of stereotype contents, associated affects, and behavioral predictions.

FIGURE 1

\section{STEREOTYPE CONTENT MODEL AND BIAS MAP}

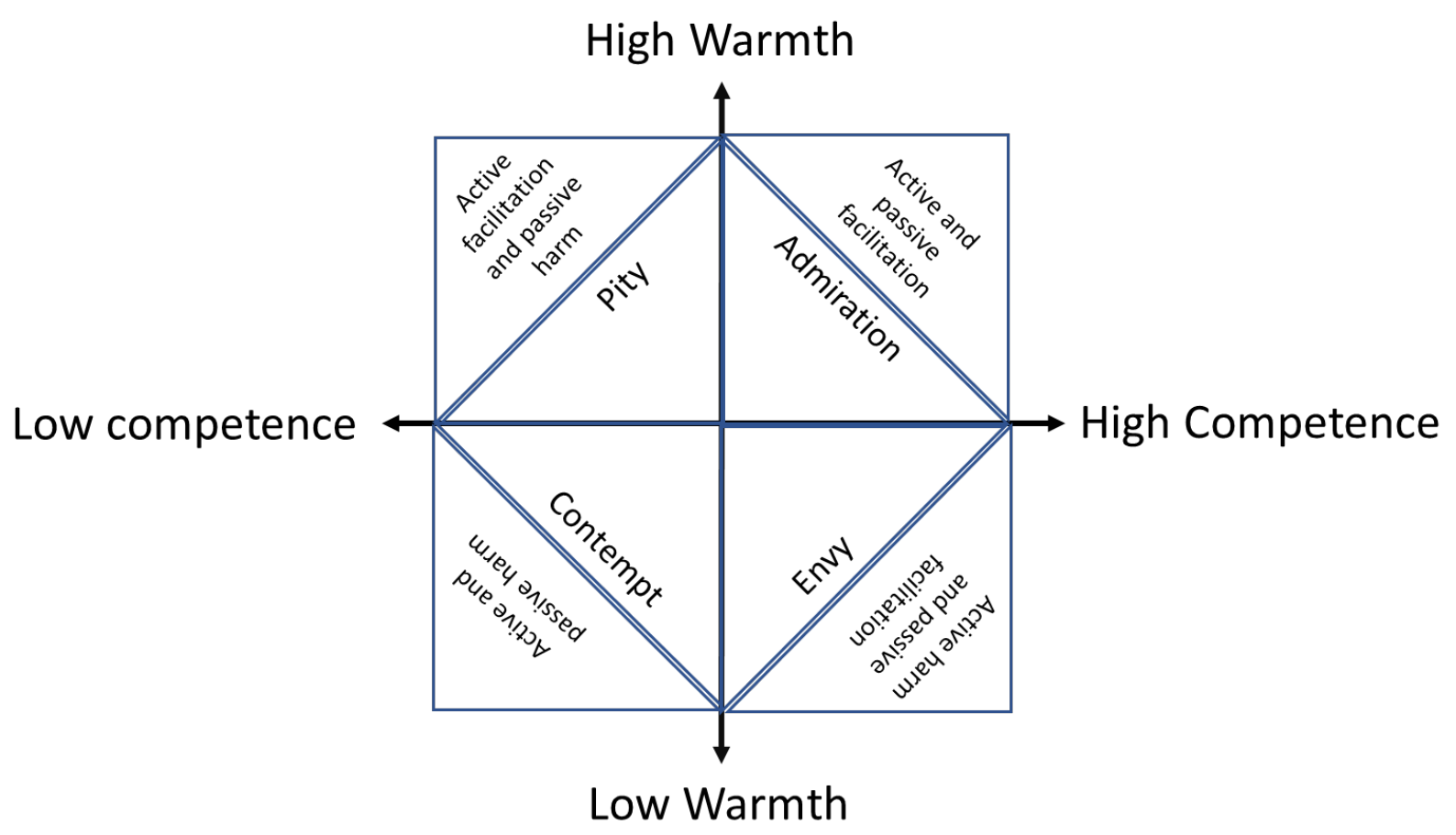

\section{Categorical Stereotypes and Firm-Based Categories}

Although the SCM and BIAS map were developed mainly for person-based categories such as race, gender, and age, consumer research studies show that they are applicable to firm and product-based categories. Starting from the idea that consumers often personalize the brands they use, consumer researchers argued that consumers ascribed person-based attributes to products and promoters of these products; stereotypes are examples of these person-based attributes (Aaker et al., 2010; Bernritter, Verlegh, \& Smit, 2016; Halkias et al., 2016). For instance, Aaker et al. (2010) showed that consumers generally stereotype non-profit firms as warm and for-profit firms as competent. The authors further argued that while consumers have generalized affinities for non-profit firms, they are more likely to patronise for-profit firms because of the perceived competence of these firms. In addition, the propensity of consumers to patronise non-profits increases when non-profits' competency scores improve. In another study, Barbarossa et al. (2016) showed that stereotypes about a firm's country of origin determine how firms were blamed for a major product recall scandal. For example, in 2012 it was discovered that some firms mixed horsemeat with meat they marketed as beef. Barbarossa et al. (2016) studied what became known as the "European horsemeat scandal of 2012" and learned that Italian consumers held producers differentially responsible based on the stereotypes about producers' countries of origin. While firms from countries with high warmth stereotypes were ascribed less blame for the food scandal, firms from countries stereotyped as highly 
competent were ascribed greater blame. The latter led to lower future purchase intentions from the brands (Barbarossa et al., 2016). As these studies show, consumers use warmth and competence dimensions of stereotypes to evaluate firm-based categories. Although social psychology scholars developed SCM, the model is applicable to different empirical contexts including organization and product groups.

Beyond identifying different combinations of dimensions of stereotypes, proponents of the SCM and BIAS map have argued that different combinations of stereotype contents are associated with different types of affective dispositions. While stereotypically warm and competent categories elicit pride and admiration, stereotypically cold and incompetent categories elicit disgust and resentment (Dovidio et al., 2010). Conversely, the cold but competent categorical stereotype elicits envy and jealousy, while the warm but incompetent categories elicit pity and sympathy. These emotions are prominent in popular and scholarly discourses on organizational categories. For instance, the Fortune ${ }^{\circledR}$ most admired companies list generates buzz among different types of audiences; firms pride themselves on being mentioned on the annual list. Warm but incompetent "mom and pop" convenience stores are usually the objects of pity and sympathy in the rhetoric against the ever-expanding supermarket chain stores. Delmestri and Greenwood (2016) showed that the Italian drink, Grappa, belongs to the low warmth and low competence category. They said, "Grappa was known as a coarse spirit consumed at the margin of society by peasants and alpine soldier and was associated with artisanal and even clandestine production in hidden shacks or woodlands" (pg. 1-2). Conversely, the armaments industry represents a low warmth category. The term "merchant of death" (Vergne, 2012 pg. 1034), used in descriptions of the category, show the extremely low warmth associated with the category.

Generally, firms and audiences prefer high warmth and high competence groups, i.e., the admired groups (Sharkey, 2014). Categories with very low warmth, very low competence, or very low warmth and competence are generally classified as stigmatized categories (Delmestri \& Greenwood, 2016; Piazza \& Perretti, 2015; Vergne, 2012). That is, based on the stereotype dimensions of warmth and competence, categories can suffer different types of stigmas: stigma because of very low warmth; stigma because of very low competence; and/or stigma because of very low warmth and very low competence. How category members address these different types of stigma might vary. For instance, it might be possible for stigmatized actors who are low on warmth but high on competence to pivot to other groups based on the perception of their competence (i.e., to span multiple categories) (Vergne, 2012). On the other hand, the option to pivot might not be readily available for categories stigmatized for low warmth and competence; members of these categories might have to come up with strategies to change the stereotypes associated with their categories (Delmestri \& Greenwood, 2016). Further empirical and theoretical works are needed to untangle the antecedents and consequences of these different types of stigma.

Seminal works applying the SCM to firm and product categories are ongoing in consumer behavior research; these studies have mostly considered consumers as the primary audiences. For instance, Aaker et al. (2010) argued that while consumers think of non-profit firms as warm they view for-profit firms as competent. Because purchase decisions correlate with competence stereotypes, Aaker et al. (2010) suggested that competence might be the primary stereotype dimension. Similarly, Antonetti and Maklan (2010) argued that perceptions of the warmth stereotype might make it difficult for consumers to adopt brands that are known as being responsible. They argued that because users of responsible brands are often stereotyped as high warmth and low competence (think of stereotypes such as hippies and "tree-huggers"), consumers are wary of adopting these brands. Their study suggested that consumers would rather be associated with brands that evoke envy, i.e., the emotions associated with the cold-but-competent stereotype. However, more questions remain about applying SCM to product and firm categories. Aaker et al. (2010) suggested that the type of products that consumers are considering might influence the relative role of the warmth and competence stereotypes in purchase decisions. For instance, consumers shopping for palliative care for terminally ill relatives and loved ones might seek providers stereotyped as warm rather than competent. In addition, there may be industry categories where competence can be taken for granted; the opportunity for strategic differentiation might lie in the warmth dimension of the stereotypes. A typical example is the commercial flight industry in the United States where most airline operators are almost uniformly disliked except for few operators such as the customer-friendly Southwest Airlines. 


\section{Stereotype Inconsistence and Counterstereotype}

Often audiences respond to stereotypical cues in ways that preserve their pre-existing mindsets. Stereotype-inconsistent information and counterstereotypes are the terms used to describe information and social cues from group members that are not in line with the stereotypes associated with their social groups. Stereotypes are informational inferences about members of social categories. While it is not unusual for audiences to encounter stereotype-inconsistent information, research shows that audiences respond to these cognitive dissonances in different ways. Audiences can create subcategories to reflect the inconsistent stereotype while still maintaining the stereotypes associated with the main category (Bodenhausen, Kang, $\&$ Peery, 2012). The subcategory black professionals partly arose in response to inconsistency between African American stereotypes and audience experiences with African Americans in high paying middleclass, white collar jobs (Bodenhausen et al., 2012).

Creating subcategories is not the only strategy for dealing with counterstereotypes. Categorization is the process of grouping similar entities together. Counterstereotypes might mean the actor is dissimilar to the group; therefore, stereotype inconsistency might lead to the process of individuation. Individuation is a process where audiences pay attention to the individual characteristics of social actors and artifacts rather than their group labels (Cañadas, Rodríguez-Bailón, \& Lupiáñez, 2015). Audiences experiencing stereotype inconsistency can individuate the sources of the inconsistent information as atypical while maintaining the stereotypes associated with the social group of the actor. For instance, the individuation process is the major flaw in the argument, "I can't be a racist, because I have friends from other races" (Brewster \& Rusche, 2017; Mallinson \& Brewster, 2005). Responses to counterstereotypes also depend on the type of audience. Audiences that value cognitive closure often negatively evaluate counterstereotypical members of social categories. Everyone uses stereotypes but to varying degrees (Stern, West, \& Rule, 2015). Audiences with a strong need for cognitive closure and structure utilize group labels more than others. Straying from established stereotypes can upset the need that these audiences have for closure. This often leads to negative evaluations of the counterstereotypical members of social groups. For instance, conservative-leaning audiences tend to need more cognitive closure (compared with liberal-leaning audiences) and are more likely to sanction counterstereotypical behaviors; therefore, female candidates that display fewer feminine postures and mannerisms are less likely to win elections in conservative states (this relationship is not observed in liberal states) (Stern et al., 2015). Audiences manage counterstereotypes by creating subcategories, individuating counterstereotypical members, and/or punishing counterstereotypical members of social categories.

How audiences respond to stereotype inconsistency or counterstereotypes can inform firm categorybased reactions. There are very few instances where audiences change stereotypes because they encounter scattered stereotype inconsistencies. In essence, firms seeking to change perceptions of their firm groups might face an uphill battle if they simply react in a manner that is contrary to their groups' labels. In fact, this strategy could backfire, especially with audiences that punish counterstereotypical group members. Many firms from industries that are considered environmentally irresponsible that try to improve their environmental records are often accused of greenwashing by environmental activists. For instance, attempts made by the retail store giant, Walmart, to improve its environmental records have been dogged by accusations of greenwashing partly because of the stereotype associated with mega-retail chain stores. Alternatively, firms' actions could lead to the creation of subcategories whose stereotypical perceptions might be inconsistent with those of the main category. One key takeaway from literature on stereotypes from adjacent disciplines is that counterstereotypical behaviors alone might not be enough to alter group labels.

Shifting the focus from category members to audiences, different audiences have different tolerance levels for stereotype inconsistency. Audiences with a stronger need for cognitive closure are more likely to be skeptical of counterstereotypes (Stern et al., 2015). Audiences that are more cognitively flexible might be open to stereotype inconsistency. Stock analysts might belong to the former group while venture capitalists might be more likely to be members of latter group. Stock analysts might prefer easily classifiable firms because of the nature of their jobs (i.e., they usually specialize along industry lines); conversely, venture capitalists might want to see innovations, something that sets firms apart from their competitors 
(Pontikes, 2012; Wry et al., 2014). Stereotype inconsistency is an alternative explanation for why organizations spanning multiple categorical boundaries might be penalized for doing so. Existing explanations in organizational category literature focus on audiences' inability to fit category spanning firms within preset categories. However, studies on stereotypes suggest that some (but not all) audiences penalize category members that deviate from the labels of their categories, i.e., display stereotypes that are associated with other groups. As many studies in organization literature show, not all audiences penalize firms for spanning categories and not all category spanners are penalized. The cognitive flexibilities of audiences are pivotal to understanding whether organizations spanning categories, i.e., displaying counterstereotypes, are punished. For audiences that crave cognitive closure, spanning multiple categories, i.e., displaying counterstereotypes, might be disruptive, and could lead to penalties. Alternatively, more cognitively flexible audiences might even reward firms spanning multiple boundaries.

Lastly, firms are highly motivated and strategic social actors; firms' attempts to reshape untoward stereotypes and the tenacity with which they follow through on their proposed course of actions can test the limits of when counterstereotypes can change categorical labels (Delmestri \& Greenwood, 2016). Delmestri and Greenwood (2016) showed how an organization persistently disrupted the stereotypes associated with its category and was rewarded by the transformation of its category to higher status category. Similarly, Japanese automobiles used to be considered inferior to American automobiles; persistent strategic actions from members of the Japanese categories consistently chipped away at these low-quality stereotypes until the stereotypes changed (Cusumano, 1988). These examples tested the boundary conditions for when counterstereotypes lead to new stereotypes about social groups. There are theoretical and empirical opportunities to further explore the interactions between firms counterstereotypical actions and audiences' social evaluation of firm groups.

\section{Cross-Category Stereotyping}

Audiences use stereotypes to compare groups. They hold equivalent stereotypes about different groups; for instance, while making judgments about culpability in the European horsemeat scandal, consumers considered German firms as highly competent and Romanian firms as incompetent (Barbarossa et al., 2016). In gender stereotypes, men are considered more competent than women and women considered warmer than men (Leach, Carraro, Garcia, \& Kang, 2017). Research shows that persistent stereotypes inconsistent information that alters the stereotypes of a focal category also impacts those of adjacent categories (Maris, Claes, Van Damme, \& Hoorens, 2016; Maris \& Hoorens, 2012). For instance, whereas female leaders are believed to be more relationship-oriented (an extension of the high warmth gender stereotype), male leaders are believed to be more task-oriented (an extension of the high competence gender stereotype) (Maris et al., 2016). In a study examining these gender biases, study participants were exposed to majority male leaders who were relationship-oriented; results of study showed that participants altered their views of male and female leaders. After the experiments, female leaders were not considered more relationship-oriented than male leaders (Maris et al., 2016). Maris et al. (2016) concluded that exposure to persistent stereotype-inconsistent information not only altered the stereotypes about the focal categories, but also those of the adjacent categories.

These findings can have far-reaching implications for organization theory and competitive strategy. Organizations monitor stereotypes about their social groups (Cattani, Porac, \& Thomas, 2017; Delmestri \& Greenwood, 2016; Porac, Thomas, Wilson, Paton, \& Kanfer, 1995). If the relationship observed between stereotype inconsistency and social categories applies to firm and product groups, then organization actors must not only pay close attention to their categorical stereotypes but also those of adjacent categories. Preliminary evidence shows that cross category stereotyping hold for product categories. At its heights, American automobile industry was stereotyped as producing vehicles that were of higher quality than those produced by Japanese automakers; however, as stereotypes about Japanese automobile qualities were disconfirmed, audiences challenged the stereotypically high-quality American automobiles (Cusumano, 1988). This argument modifies the category-based competition model championed by Joseph Porac and coauthors (Cattani et al., 2017; Porac \& Thomas, 1994; Porac et al., 1995). While firms might focus their competitive behaviors on other firms in their categories, they will do well to keep an eye on the stereotypes 
of adjacent product groups. Changes in the stereotypes of these adjacent groups can disrupt audiences' social evaluations of the groups of the focal firms and consequently impact their competitive dynamics.

\section{DISCUSSION AND CONCLUSION}

Scholars in many disciplines study categories and classification systems as part of their work. Almost all systemic bodies of knowledge explore the concept of categories (Allen, 2000; Grabb, 2016; Linton, 1942; Phipps, 1982; Tilly, 1998; Tomaskovic-Devey, Avent-Holt, Zimmer, \& Harding, 2009; Vila, 2000; Whitehead, 2009). Categories arrange overwhelming numbers of stimuli into manageable headings for social actors (Bodenhausen et al., 2012; Jacob, 2004; Roy, 2004). Social actors learn about entities based on the entities' categories. However, the organization studies of categories do not reflect the width of insights on the topic; knowledge of firm categories is based on narrow segments of the vast literature on the subject. Specifically, in this paper we address how categories influence the actions of audiences and reactions of categorized firms. Previous studies in organization literature addressed these actions and reactions grouping in less systemic ways. For instance, while some argued that spanning multiple categories lead audiences to penalize firms, others contend that this might not always be the case. In addition, while conventional theoretical conclusions suggest firms should reduce the number of product groups, some firms seem to favor spanning multiple product groups; that is, there is a disconnect between theoretical postulations and empirical realities of many firms. We argued that this is because scholars have ignored what it means to be members of different firm groups. Beyond grouping, categories are bases for inferences about their members. Some scholars conceptualized these inferences as stereotypes. Stereotypes that audiences hold about social groups are transferred to members of these groups. Stereotypes can be positive and negative. We argue that these labels can shed light on the actions of audiences and reactions of group members. Categorical stereotypes can make members want to distance themselves from these categories. One way of distancing from a focal category is by affiliating with other categories, i.e., spanning categories (Vergne, 2012).

In addition, we argued that the introduction of stereotypes to organization literature will remove the pretense of impartiality of audiences. Audiences have different preferences for social groups; that is, audiences value some social groups more than others. Stereotypes make this dimension of categorization salient. Building on the seminal works of scholars in social and cognitive psychology, we show how labels attached to groups might shape the actions of audiences and reactions of group members. Stereotypes vary on two dimensions of warmth and competence. Warmth captures the intentions of members of social groups towards the audiences while competence captures the group's ability to execute its intentions. Groups can be stereotyped as high warmth, high competence; low warmth, low competence; low warmth, high competence; and high warmth, low competence. The SCM and BIAS map models propose different emotions and actions that might result from these different labels. These models are relevant to our understanding of category-inspired actions and reactions because both audiences and grouped firms respond to the labels attached to the group. Firm groups can be admired, envied, pitied, or despised by their audiences. These stereotypes can inform why firms might want to span group boundaries.

Generally, a firm's category scale of preference should have the admired categories at the top, followed by the envied categories; the pitied categories should be third, and the despised category should be last. Firm's reactions to been categorized can be interpreted as trying to move up from lower levels of this category scale of preference, to higher levels. That is, while a firm in the despised category might attempt to affiliate with firm categories in any of the pitied, envied, and/or admired categories, a firm in a pitied category might attempt to affiliate with envied and/or admired categories. Lastly, firms from the envied categories will likely strive to be members of the admired categories. With firms attempting to improve the stereotypes associated with their categories, scholars should not be surprised by the prevalence of category spanning; in fact, based on categorical stereotype arguments, category spanning should be expected from most firms that are not members of the admired groups. Figure 2 shows the firms' category scale of preference based on categorical stereotypes; firms are expected to span boundaries to high level categories. 
FIGURE 2

\section{CATEGORY SCALE OF PREFERENCE}

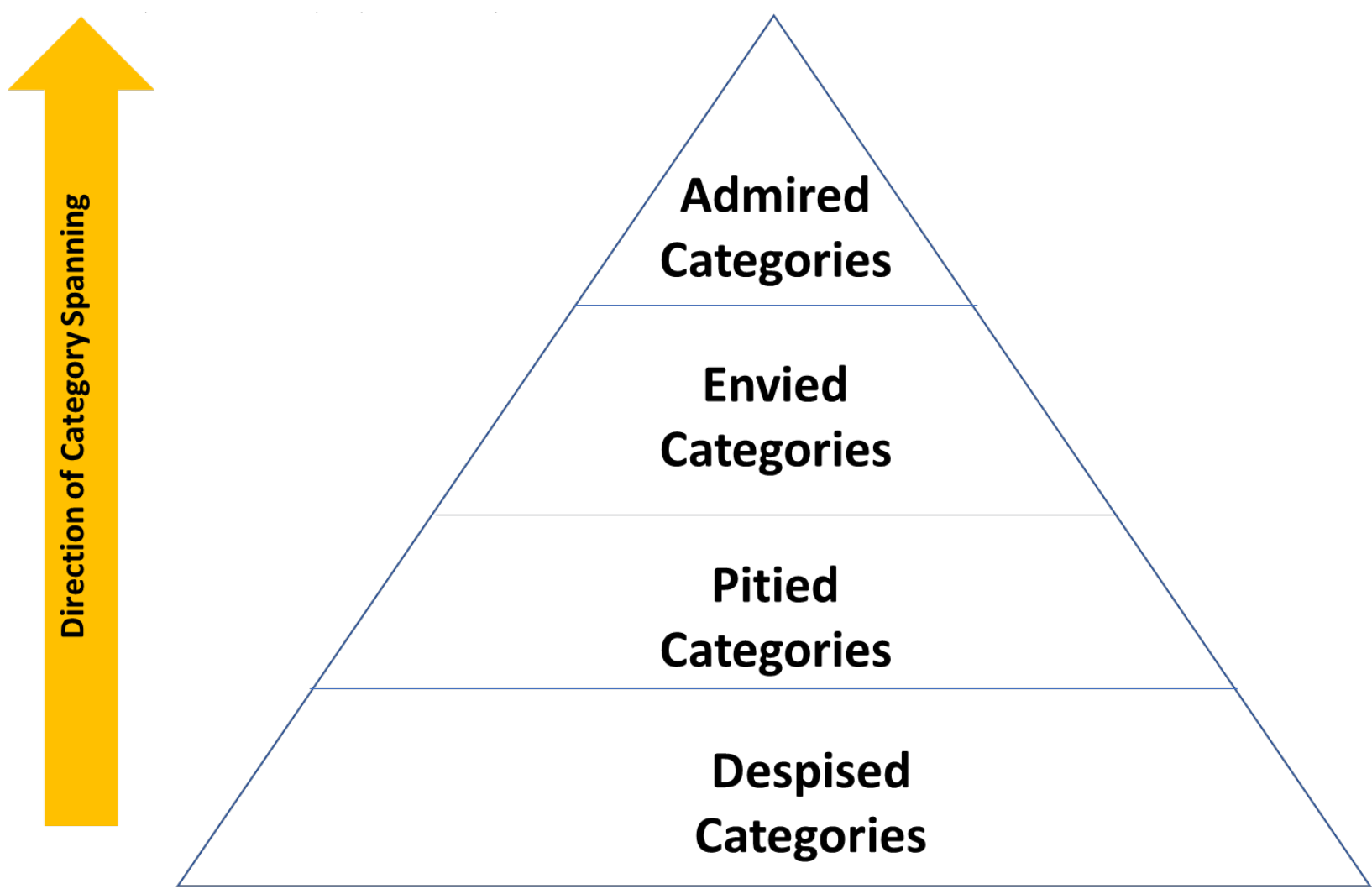

Spanning categories is not the only strategy available to firms that want to improve the stereotypes of their groups. Firms can simply exit the said categories. Piazza and Perretti (2015) argued that many firms exited nuclear power generation because of the labels associated with the product. More subtle engagements could include attempts to reinvent the label of the groups; labels are socially constructed (Delmestri \& Greenwood, 2016). Firms strategic actions can change the stereotypes associated with their groups. Firms attempting to redefine the labels of the group can also deliberately or inadvertently create new product categories (or at least create subcategories whose stereotypes contrast with those of the main category). For instance, the category ridesharing partly emerged because of negative stereotypes associated with the taxicab industry (Anderson, 2014; Wallsten, 2015). Understanding stereotypes and how firms respond to the stereotypes of their categories can reconcile the incongruence between category research in organization studies and firm practices.

It is likely that audiences will value warmth and competence differently. While shareholders might emphasize competence over warmth, potential employees, environmentalists, and community stakeholders might put more emphasis on warmth. In fact, one of the key assumptions of agency theory, a leading perspective in financial corporate governance analysis, is the belief that owners and managers of organizations might be competing for the allocation of the resources of the firms; competition between social groups is the foundation of the warmth stereotype. That is, corporation governance arrangements designed along the stipulates of agency theory were meant to tackle the low warmth stereotypes that shareholders had about managers of major corporations. Conversely, audiences, such as environmental activists, view firms' activities in terms of the overall impacts that these activities have on social and environmental resources; therefore, these audiences will care more about warmth stereotypes when evaluating firms. Also, at the entrepreneurial stage as well as when new categories are emerging and it might be difficult to ascertain what constitutes competence, audiences might be more likely to look for 
stereotypes that capture characteristics such as trust, dependability, and moral suasion; these are adjectives associated with warmth stereotypes.

Different audiences can hold different stereotypes about the same firm group. This partly explains why some organizations are simultaneously admired and despised (Vergne 2012). Firms can count on having allies in audiences that admire them and antagonists in audiences that despise/envy them. Responses to categorical stereotypes reflect stakeholders' sentiments and the salience of contextual factors. While category members might not want to alienate their admirers, they might be forced by situational factors to concede to the demands of other audiences including those that despised/envied them. How much firms rely on audiences for financial and social supports might also influence how they respond to stereotypes about their categories. Taking an approach to categorization that relies on stereotypes forces scholars to group audiences based on how these audiences label firm categories.

Separating types of category-based actions and reactions will be beneficial for categorical studies in organization research. Up until now, these actions and reactions have been delineated only along the valence dimension, i.e., harm versus facilitation. The intensity dimensions, i.e., active versus passive have been ignored in organization literature on categories. For instance, failing to provide coverage, a passive harm, is treated in the same manner as massive protests that can disrupt organizational activities, which fall under the definition of active harm. It is reasonable to think that group members and their audiences will respond differently to these varied patterns of actions. One set of actions might require more aggressive category alignment strategies than others. Piazza and Perretti (2015) argued that some resistance to stigmas drives organizations to abandon product categories rather than to mask the stigma through spanning as suggested by Vergne (2012). Piazza and Perretti (2015) suggested that the intensity of audiences' actions plays pivotal roles in dictating organizational strategy. Taken together, these studies suggest that the intensity of audiences' responses is a key determinant of whether group members affiliate with other groups or adopt an alternative strategy. In the Piazza and Perretti (2015) study, that strategy is to abandon the firm group. In the Delmestri and Greenwood (2016) study, that strategy is to reinvent product stereotypes. Categorized firms' behavioral responses to group affiliation depend on the valence and intensity of audiences' actions.

\section{Future Research Directions}

Categorical stereotypes can open new avenues for categories research in organization studies. Stereotypes are social evaluations associated with firm groups. Audiences judge group members not only on their proximity to prototypical members, but also on the group's stereotypes. How these judgments affect firms' reactions and responses have not been properly explored in organizational research. Reactions to negative stereotypes can lead to category spanning and/or the emergence of new categories. The mechanisms through which this labelling leads to various group alignments and realignments strategies are understudied. Similarly, different audiences can hold different stereotypes for the same firm category. We have limited knowledge of how firms respond to different and conflicting stereotypes. Studies about decoupling might provide guidance for how organizations can respond to conflicting stereotypes. Scholars have argued that organizations respond to conflicting pressures by decoupling actions and responses across audiences and across time. The extent to which these strategies can be successful is an important empirical question; this is partly because while decoupling, as we know it, operates at the organization level, stereotypes operate at the category level.

Some scholars argue that stereotypes can only lead to stigmas when the audiences are more powerful than the categorized population (Link \& Phelan, 2001). However, this assertion is based on person-based categorical stigmas. The links between group stereotypes and group stigmas present another avenue for fruitful future research. The mechanisms through which negative stereotypes lead to stigmas are underresearched in organization studies. Another possible research topic is what form of power or social capital will audiences possess to be able to stigmatize firm groups based on negative categorical stereotypes? In addition, the SCM and BIAS map models link stereotypes with emotions directed towards categories; the emotional consequences of a category are additional avenues for further research. Categorical stereotypes are cognitive structures with emotional consequences. The absence of research on emotional implications of categories is interesting because a basic tenet of organization category literature is that grouping firms 
together draws responses from firms and their audiences. However, research in psychology shows that emotions predict actions better than cognitions (Cuddy et al., 2007). Scholars interested in category-based actions will profit from understanding category-inspired emotions. In addition, how emotions translate into actions among audiences and grouped firms still needs to be understood. At the individual level, some emotions lead to actions while others create inertia. More empirical and theoretical works are needed to untangle the relationship between stereotype-inspired emotions and actions of audiences as well as reactions of categorized firms. Lastly, scholars need to pay attention to the intensity dimensions of category-inspired actions. Extant research on firm groups discuss category-based actions only along valence dimensions (i.e., harm and facilitation) and neglect the intensity dimensions (i.e., active and passive). Pragmatically, firms could ignore passive threats with limited consequences; however, active threats due to stereotypes can have dire consequences. This intensity dimension might hold the key to how categorized firms react to audiences' actions.

Our study draws extensively from stereotype scholarship in cognitive and social psychology. This literature focuses on person-based categories. Building on ongoing scholarship in consumer research, we have argued that firm- and product-based categories are also stereotyped. Extant studies in psychology have suggested that warmth is the primary stereotype dimension and that it influences active behavior; firm- and product-based categories might provide the boundary conditions for this argument. Preliminary works in consumer research show that competence might be the primary stereotype dimension for many audiences (Aaker et al., 2010). Investors and analysts expect organizations to meet key criteria such as quarterly earnings. Further scholarly works are needed to uncover the dynamics of the two dimensions of stereotypes in firm and product categories. If competence is the primary stereotype in firm categories, will it also be the antecedent of active behaviors?

\section{Managerial Implications}

The disconnect between firms' category-based reactions and category scholarship in organization studies is the starting point of our paper; some managers seem to act contrary to the conclusions of the literature on firm categories. We suggest that this might be because managers respond not only to been categorized, but also to the stereotypes of their groups. For instance, despite all the admiration of Silicon Valley-based technology firms, the sexist stereotypes associated with these firm categories are not going away and they are painting members of this group in bad lights. Often, Managers respond to these stereotypes; their responses might lead to what scholars refer to as category spanning. However, as the theories on stereotypes suggest and the Silicon Valley sexist stereotypes seemed to reveal, acting counterstereotypical does not automatically change group stereotypes. Despite multiple actions and assurances to the contrary, the narrative that Silicon Valley is sexist is not abating. Stereotyped firms need to go beyond acting counterstereotypically to change the labels of their groups. This is partly because audiences interpret counterstereotypical actions stereotypically. To successfully change labels, firms might need buy-in from key audiences. Also, managers need to understand that context can influence how vulnerable their firms are to stereotypes and category-induced actions. Untoward events can refocus audiences' attention to labels about specific organization groups. The 9/11 terrorist attacks accentuated negative stereotypes associated with the global armaments industry (Vergne, 2012). Lastly, managers pay attention to stereotypes of their groups, but often neglect those of adjacent groups (Porac \& Thomas, 1994). Studies in cross-category stereotyping suggest that changes to stereotypes of adjacent categories can affect the labels of closely related categories. The change to the low-quality stereotypes of Japanese automobiles made audiences challenged the higher quality stereotypes of their American counterparts. It is in the interest of managers to not only monitor the labels of their firm groups, but also those of closely related firm groups. 


\section{REFERENCES}

Aaker, J.L., Vohs, K.D., \& Mogilner, C. (2010, August). Nonprofits Are Seen as Warm and For-Profits as Competent: Firm Stereotypes Matter. Journal of Consumer Research, 37, 224-237. https://doi.org/10.1086/651566

Allen, N.J. (2000). Categories and Classifications: Maussian Reflection on the Social. New York, NY: Berghahn Books.

Anderson, D.N. (2014). "Not just a taxi"? For-profit ridesharing, driver strategies, and VMT. Transportation, 41(5), 1099-1117. https://doi.org/10.1007/s11116-014-9531-8

Antonetti, P., \& Maklan, S. (2016). Hippies, Greenies, and Tree Huggers: How the "Warmth" Stereotype Hinder the Adoption of Responsible Brands. Psychology \& Marketing, 30(6), 461-469. https://doi.org/10.1002/mar

Ayduk, O., May, D., Downey, G., \& Higgins, E.T. (2003). Tactical differences in coping with rejection sensitivity: The role of prevention pride. Personality and Social Psychology Bulletin, 29(4), 435448. https://doi.org/10.1177/0146167202250911

Barbarossa, C., De Pelsmacker, P., Moons, I., \& Marcati, A. (2016). The influence of country-of-origin stereotypes on consumer responses to food safety scandals: The case of the horsemeat adulteration. Food Quality and Preference, 53, 71-83. https://doi.org/10.1016/j.foodqual.2016.05.015

Bernritter, S.F., Verlegh, P.W.J., \& Smit, E.G. (2016). Why Nonprofits Are Easier to Endorse on Social Media: The Roles of Warmth and Brand Symbolism. Journal of Interactive Marketing, 33, 2742. https://doi.org/10.1016/j.intmar.2015.10.002

Bodenhausen, G.V., Kang, S.K., \& Peery, D. (2012). Social Categorization and perception of social groups. In The Sage Handbook on Social Cognition (pp. 311-329). London: Sage Publications.

Brewster, Z.W., \& Rusche, S.N. (2017). The Effects of Racialized Workplace Discourse on Race-Based Service in Full-Service Restaurants. Journal of Hospitality \& Tourism Research, 41(4), 398-414. https://doi.org/10.1177/1096348014538051

Brubaker, R., Loveman, M., \& Stamatov, P. (2004). Ethnicity as cognition. Theory and Society, 33(1), 31-64. https://doi.org/10.1023/B:RYSO.0000021405.18890.63

Cañadas, E., Rodríguez-Bailón, R., \& Lupiáñez, J. (2015, October). The effect of social categorization on trust decisions in a trust game paradigm. Frontiers in Psychology, 6, 1-9. https://doi.org/10.3389/fpsyg.2015.01568

Cattani, G., Porac, J.F., \& Thomas, H. (2017). Categories and Competition. Strategic Management Journal, 38, 64-92. https://doi.org/10.1002/smj

Cuddy, A.J., Fiske, S.T., \& Glick, P. (2008). Warmth and Competence as Universal Dimensions of Social Perception: The Stereotype Content Model and the BIAS Map. Advances in Experimental Social Psychology, 40(7), 61-149. https://doi.org/10.1016/S0065-2601(07)00002-0

Cuddy, A.J.C., Fiske, S.T., \& Glick, P. (2007). The BIAS map: Behaviors from intergroup affect and stereotypes. Journal of Personality and Social Psychology, 92(4), 631-648. https://doi.org/10.1037/0022-3514.92.4.631

Cusumano, M.A. (1988). Manufacturing Innovation: Lessons From The Japanese Auto Industry. Sloan Management Review, 30(1), 29-39.

Delmestri, G., \& Greenwood, R. (2016). How Cinderella Became a Queen: Theorizing Radical Status Change. Administrative Science Quarterly, pp. 1-44. https://doi.org/10.1177/0001839216644253

Diestre, L., \& Rajagopalan, N. (2014). Toward an input-based perspective on categorization: Investor reactions to chemical accidents. Academy of Management Journal, 57(4), 1130-1153. https://doi.org/10.5465/amj.2011.1096

Dovidio, J.F., Hewstone, M., Glick, P., \& Esses, V.M. (2010). Prejudice, Stereotyping and Discrinination: Theoretical and Empirical Overview. In J.F. Dovidio, M. Hewstone, P. Glick, \& V.M. Esses (Eds.), The Sage Handbook of Prejudice, Stereotyping and Discrimination 2 (pp. 3-28). London: Sage Publications. 
Durand, R., \& Paolella, L. (2013). Category stretching: Reorienting research on categories in strategy, entrepreneurship, and organization theory. Journal of Management Studies, 50(6), 1100-1123. https://doi.org/10.1111/j.1467-6486.2011.01039.x

Fiske, S.T., Cuddy, A.J., Glick, P., \& Xu, J. (2002). A model of (often mixed) stereotype content: Competence and warmth respectively follow from perceived status and competition. Journal of Personality and Social Psychology, 82(6), 878-902. https://doi.org/10.1037/0022-3514.82.6.878

Glynn, M.A., \& Navis, C. (2013). Categories, identities, and cultural classification: Moving beyond a model of categorical constraint. Journal of Management Studies, 50(6), 1124-1137. https://doi.org/10.1111/joms. 12023

Grabb, E.G. (2016). Marxist Categories and Theories of Class: The Case of Working-Class Authoritarianism. The Pacific Sociological Review, 23(4), 359-376.

Halkias, G., Davvetas, V., \& Diamantopoulos, A. (2016). The interplay between country stereotypes and perceived brand globalness/localness as drivers of brand preference. Journal of Business Research, 69(9), 3621-3628. https://doi.org/10.1016/j.jbusres.2016.03.022

Jacob, E.K. (2004). Classification and Categorization: A Difference that makes a Difference. Library Trends, 52(3), 515-540. https://doi.org/10.1007/s11406-014-9559-1

Jones, C., Maoret, M., Massa, F.G., \& Svejenova, S. (2012). Rebels with a Cause: Formation, Contestation, and Expansion of the De Novo Category "Modern Architecture," 1870-1975. Organization Science, 23(6), 1523-1545. https://doi.org/10.1287/orsc.1110.0701

Kennedy, M.T. (2008). Getting Counted: Markets, Media, and Reality. American Sociological Review, 73, 270-295. https://doi.org/10.1177/000312240807300205

Khaire, M. (2014). Fashioning an Industry: Socio-cognitive Processes in the Construction of Worth of a New Industry. Organization Studies, 35(1), 41-74. https://doi.org/10.1177/0170840613502766

Leach, C.W., Carraro, L., Garcia, R.L., \& Kang, J.J. (2017). Morality stereotyping as a basis of women's in-group favoritism: An implicit approach. Group Processes and Intergroup Relations, 20(2), 153-172. https://doi.org/10.1177/1368430215603462

Link, B.G., \& Phelan, J.C. (2001, May). Conceptualizing Stigma. Annual Review of Sociology, 27, 363385.

Linton, R. (1942). Age and Sex Cateories. American Sociological Review, 7(5), 589-603.

Mallinson, C., \& Brewster, Z.W. (2005). "Blacks and bubbas": Stereotypes, ideology, and categorization processes in restaurant servers' discourse. Discourse \& Society, 16(6), 787-807. https://doi.org/10.1177/0957926505056664

Maris, S., Claes, J., Van Damme, C., \& Hoorens, V. (2016). Indirect stereotype change in artificial and real-life stereotypes. Social Cognition, 34(1), 55-80. https://doi.org/http://dx.doi.org/101521 soco201634155

Maris, S., \& Hoorens, V. (2012). The ISI Change phenomenon: When contradicting one stereotype changes another. Journal of Experimental Social Psychology, 48(3), 624-633. https://doi.org/10.1016/j.jesp.2012.01.001

Ozcan, P., \& Santos, F.M. (2015). The Market that Never Was: Turf Wars and Failed Alliances in Mobile Payment. Strategic Management Journal, 36, 1486-1512. https://doi.org/10.1002/smj

Phipps, P.M. (1982). The Merging Categories: Appropriate Education or Administrative Convenience? Journal of Learning Disabilities, 15(2), 153-154.

Piazza, A., \& Perretti, F. (2015). Categorical Stigma and Firm Disengagement: Nuclear Power Generation in the United States, 1970-2000. Organization Science, 26(3), 724-742. https://doi.org/10.1287/orsc.2014.0964

Pontikes, E.G. (2012). Two Sides of the Same Coin: How Ambiguous Classification Affects Multiple Audiences' Evaluations. Administrative Science Quarterly, 57(1), 81-118. https://doi.org/10.1177/0956797609357327

Porac, J.F., \& Thomas, H. (1994). Cognitive categorization and subjective rivalry among retailers in a small city. Journal of Applied Psychology, 79(1), 54-66. https://doi.org/10.1037/00219010.79.1.54 
Porac, J.F., Thomas, H., Wilson, F., Paton, D., \& Kanfer, A. (1995). Rivalry and the industry model of Scottish knitwear producers. Administrative Science Quarterly, 40(2), 203-227. https://doi.org/10.2307/2393636

Roberts, P.W., Simons, T., Swaminathan, A., \& Lounsbury, M. (2010). Crossing a categorical boundary: The implications of switching from non-kosher wine production in the Israeli wine market. In Categories in Markets: Origins and Evolution: Research in the Sociology of Organizations (Vol. 31). https://doi.org/10.1108/S0733-558X(2010)0000031007

Roy, W.G. (2004). "Race records" and "hillbilly music": Institutional origins of racial categories in the American commercial recording industry. Poetics, 32(3-4), 265-279. https://doi.org/10.1016/j.poetic.2004.06.001

Schultz, P.L., Marin, A., \& Boal, K.B. (2014). The impact of media on the legitimacy of new market categories: The case of broadband internet. Journal of Business Venturing, 29(1), 34-54. https://doi.org/10.1016/j.jbusvent.2012.11.001

Sharkey, A.J. (2014). Categories and Organizational Status: The Role of Industry Status in the Response to Organizational Deviance. American Journal of Sociology, 119(5), 1380-1433. https://doi.org/10.1086/675385

Stern, C., West, T.V., \& Rule, N.O. (2015). Conservatives negatively evaluate counterstereotypical people to maintain a sense of certainty. Proceedings of the National Academy of Sciences, 112(50), 201517662. https://doi.org/10.1073/pnas.1517662112

Tilly, C. (1998). Durable Inequality. Berkeley: University of Carlifonia Press.

Tomaskovic-Devey, D., Avent-Holt, D., Zimmer, C., \& Harding, S. (2009). The categorical generation of organizational inequality: A comparative test of Tilly's durable inequality. Research in Social Stratification and Mobility, 27(3), 128-142. https://doi.org/10.1016/j.rssm.2009.04.004

Vergne, J-P. (2012). Stigmatized categories and public disapproval of organizations: A mixed-methods study of the global arms industry, 1996-2007. Academy of Management Journal, 55(5), 10271052. https://doi.org/10.5465/amj.2010.0599

Vergne, J-P., \& Wry, T. (2014). Categorizing categorization research: Review, integration, and future directions. Journal of Management Studies, 51(1), 56-94. https://doi.org/10.1111/joms.12044

Vila, P. (2000). Cross borders, Reinforcing Borders. Austin, TX: University of Texas Press.

Villano, P., Fontanella, L., Fontanella, S., \& Donato, M.D. (2017). Stereotyping Roma people in Italy: IRT models for ambivalent prejudice measurement. International Journal of Intercultural Relations, 57, 30-41. https://doi.org/10.1016/j.ijintrel.2017.01.003

Wallsten, S. (2015). The Competitive Effects of the Sharing Economy: How is Uber Changing Taxis? Washington, DC.

Whitehead, K.A. (2009). "Categorizing the Categorizer": The Management of Racial Common Sense in Interaction. Social Psychology Quarterly, 72(4), 325-342. https://doi.org/10.1177/019027250907200406

Wry, T., Lounsbury, M., \& Jennings, P.D. (2014). Hybrid Vigor: Securing Venture Capital By Spanning Categories in Nanotechnology. Academy of Management Journal, 57(5), 1309-1333. Retrieved from http://10.0.21.89/amj.2011.0588

Zhao, E.Y., Ishihara, M., \& Lounsbury, M. (2013). Overcoming the Illegitimacy Discount: Cultural Entrepreneurship in the US Feature Film Industry. Organization Studies, 34(12), 1747-1776. https://doi.org/10.1177/0170840613485844

Zuckerman, E.W. (1999). The Categorical Imperative: Securities Analysts and the Illegitimacy Discount. American Journal of Sociology, 104(5), 1398-1438. https://doi.org/10.2307/2182813

Zuckerman, E.W. (2000). Focusing the Corporate Product: Securities Analysts and De-diversification. Administrative Science Quarterly, 45(3), 591-619. https://doi.org/10.2307/2667110 